\title{
Estudo de revisão sistemática sobre o uso do conceito de cotidiano no campo da terapia ocupacional no Brasil ${ }^{1}$
}

\author{
Mariana Moraes Salles ${ }^{a}$, Thelma Simóes Matsukura ${ }^{b}$

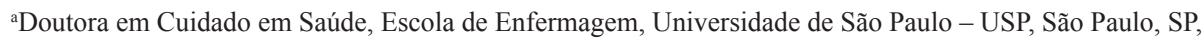 \\ Brasil, Pós-doutoranda, Departamento de Terapia Ocupacional, Centro de Ciências Biológicas e da Saúde, \\ Universidade Federal de São Carlos - UFSCar, São Carlos, SP, Brasil

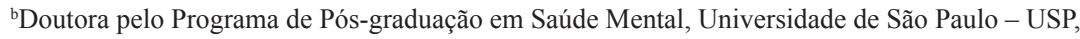 \\ Ribeirão Preto, SP, Brasil, Docente dos Programas de Pós-graduação em Terapia Ocupacional e de \\ Pós-graduação em Educação Especial, Departamento de Terapia Ocupacional, \\ Centro de Ciências Biológicas e da Saúde, Universidade Federal de São Carlos - UFSCar, São Carlos, SP, Brasil
}

\begin{abstract}
Resumo: No campo da terapia ocupacional o interesse pelo conceito de cotidiano vem crescendo, com estudos que se referem à questão da vida cotidiana como ferramenta tanto teórico-conceitual como prática, que pode auxiliar pesquisas e a atenção em terapia ocupacional. O objetivo deste estudo é identificar e sistematizar a produção de conhecimento no Brasil, na área de terapia ocupacional, sobre o conceito de cotidiano. Como metodologia foi realizada uma revisão sistemática da literatura nacional, nos últimos 10 anos, sobre o conceito de cotidiano na terapia ocupacional. Foram selecionados 12 artigos para integrar a pesquisa. $\mathrm{O}$ conceito de cotidiano, considerado nas investigações realizadas por terapeutas ocupacionais, se estabelece na relação entre aquilo que é singular do sujeito com o que é coletivo e social. Esse conceito define uma posição teórica da terapia ocupacional, que rompe com uma interpretação médica e positivista dos cuidados em saúde e se preocupa com a subjetividade do sujeito, suas atividades no dia a dia e sua inserção social. O conceito de cotidiano também foi utilizado para a reflexão sobre como o adoecimento causa transformações na vida cotidiana das pessoas, para embasar a descrição e análise da vida cotidiana dos sujeitos que eram foco dos estudos e para discutir sobre o cotidiano na prática da terapia ocupacional. São diversas as possibilidades do uso do conceito de cotidiano na pesquisa e na prática da terapia ocupacional, e o presente estudo evidencia que esse construto/conceito soma ao aporte teórico vinculado ao conhecimento em terapia ocupacional contemporâneo brasileiro.
\end{abstract}

Palavras-chave: Terapia Ocupacional, Cotidiano, Literatura de Revisão como Assunto.

\section{Systematic review study on the use of the concept of daily life in the field of occupational therapy in Brazil}

\begin{abstract}
Interest in the concept of daily life has increased in the field of occupational therapy, with studies referring to daily life as a tool that is both theoretic-conceptual and practical, providing support for both research and care. In this study, we aimed to identify and systematize the knowledge production about the daily life concept in occupational therapy in Brazil. A systematic review of the Brazilian literature of the past ten years on the concept of daily life in occupational therapy was used as our methodological approach. Twelve articles were selected to compose this research. The concept of daily life, as considered in studies of occupational therapists, is established in the relationship between what is singular to the individual and what is collective and social. This concept defines a theoretical position in occupational therapy, departing from a medical and positivist
\end{abstract}

Autor para correspondência: Mariana Moraes Salles, Universidade Federal de São Carlos, Rod. Washington Luís, Km 235, Monjolinho, CEP 13565-905, São Carlos, SP, Brasil, e-mail: marianamsalles@ gmail.com

Recebido em 26/4/2013; Aceito em 03/06/2013. 
interpretation of health care, giving attention to the subjectivity of individuals, their day-to-day activities and their social inclusion. The concept of daily life was also used in the reflection about how illnesses change people's daily lives, to support the description and analysis of the daily lives of the studied subjects and to discuss the concept of daily life in occupational therapy practice. There is a wide range of possibilities for the use of the concept of daily life in the research and practice of occupational therapy. The present study shows that this concept adds to the basis of contemporary occupational therapy knowledge produced in Brazil.

Keywords: Occupational Therapy, Daily Life, Literature Review as Topic.

\section{Introdução}

No campo da terapia ocupacional o interesse pelo estudo do conceito de cotidiano vem crescendo, com pesquisas produzidas por terapeutas ocupacionais, que se referem à questáo da vida cotidiana como uma ferramenta tanto teórico-conceitual como prática, que pode auxiliar na atenção em terapia ocupacional (GALHEIGO, 2003; FRANCISCO, 2001; DRUMMOND, 2007; BENETTON; TEDESCO; FERRARI, 2003).

Desde o início da terapia ocupacional havia o interesse sobre como as pessoas vivem sua vida, sendo as concepçóes sobre hábitos, desenvolvidas por Eleonor Slagle, um dos fundamentos da profissão. Acreditava-se que hábitos saudáveis levariam a uma vida mais saudável (DRUMMOND, 2007).

A partir do século XXI se inicia o interesse da terapia ocupacional pelo conceito de cotidiano, baseando os princípios teóricos em autores da filosofia como Lukács, Heller e Certeau (DRUMMOND, 2007). A terapia ocupacional se interessa pelas atividades realizadas pelos sujeitos, e essas atividades são desempenhadas no dia a dia, na vida cotidiana. É a partir dessas atividades que as pessoas se relacionam entre si, participam do processo produtivo da sociedade, vivenciam a cultura da qual fazem parte e se tornam quem elas são. No processo de realização de atividades em terapia ocupacional vai se estabelecendo uma forma de fazer e de se relacionar que envolve a construçáo da qualidade de vida cotidiana (CASTRO; LIMA; BRUNELLO, 2001).

Conforme abordam Castro, Lima e Brunello (2001). qualidade de vida envolve a compreensão subjetiva das pessoas sobre seu bem-estar e sua situação de vida. Envolve também o investimento para uma organização coletiva de sujeitos que exercem seus direitos e vivenciam a cidadania. Ela é, ao mesmo tempo, um processo singular e coletivo. As autoras compreendem que a vida se apresenta como um leque de açóes rotineiras e a construção da vida cotidiana refere-se à transformaçáo concreta da realidade.
$\mathrm{Na}$ terapia ocupacional, as atividades possibilitam ao sujeito reconhecer-se e ser reconhecido pelos outros, o fazer e as atividades realizadas pelo indivíduo contam a história da vida de cada um. É nesse resgate da história do sujeito, permeado pelas atividades, que se encontra o território onde se descobrem interesses, capacidades e potencialidades que tracejam caminhos possíveis no campo das produçóes humanas. As práticas da terapia ocupacional, centradas no fazer humano, visam a construção de um cotidiano potencializado, que possibilita constituir o bem-estar pessoal do sujeito (CASTRO; LIMA; BRUNELLO, 2001).

É no desenvolvimento da vida cotidiana, enquanto construção individual no meio social, que se constrói o raciocínio clínico da terapia ocupacional.

A clínica da terapia ocupacional é criada no encontro de um cotidiano possível, pois ele é ou foi violentamente transformado, pela sua interrupção e não pela sua supressão (BENETTON; TEDESCO; FERRARI, 2003, p. 38).

Assim, terapeutas ocupacionais têm procurado estudar o cotidiano como forma de compreender melhor o campo da terapia ocupacional. Porém, utilizar o cotidiano como base para análise das avaliações, das práticas e dos resultados em terapia ocupacional ainda representa uma tarefa difícil de ser executada (DRUMMOND, 2007).

Dessa forma, é possível depreender que interessa para a terapia ocupacional o que as pessoas fazem, como usam o tempo, onde vão, quais são seus desejos, como o contexto social facilita ou dificulta o engajamento das pessoas em diferentes atividades; enfim, como se constrói a vida cotidiana dos sujeitos.

A terapia ocupacional preocupa-se com a produção de vida das pessoas que atende, e a vida é composta no cotidiano; é nas pequenas açóes do dia a dia que nos construímos enquanto seres humanos e desenvolvemos nossos interesses. Cada cotidiano é vivido de forma particular, única por cada sujeito, 
construído conforme a singularidade do sujeito e da realidade vivida pelo contexto social. Dessa forma, a construção e transformação da vida cotidiana pode se apresentar como um instrumento na atenção em terapia ocupacional; assim como uma finalidade a ser alcançada em terapia ocupacional.

O objetivo deste estudo foi identificar e sistematizar a produçáo de conhecimento na área de terapia ocupacional sobre o conceito de cotidiano no Brasil.

\section{Metodologia}

Como metodologia foi realizada uma revisão sistemática da literatura sobre o conceito de cotidiano na terapia ocupacional. A revisão de literatura é uma síntese de todas as pesquisas relacionadas com uma questão específica; com uma pergunta sobre a causa, o diagnóstico ou o prognóstico de um problema de saúde, por exemplo. A revisão sistemática difere da revisão tradicional uma vez que procura superar vieses seguindo um método preestabelecido na busca, seleção e avaliação das pesquisas; e na coleta, síntese e interpretação dos dados oriundos das pesquisas (GALVÂO; SAWADA; TREVIZAN, 2004). A questão norteadora utilizada na presente pesquisa foi: Qual o desenvolvimento do uso do conceito de cotidiano em terapia ocupacional e como esse conceito tem sido utilizado atualmente?

\subsection{Procedimentos}

Lima, Pastore e Okuma (2011), em estudo de revisão sistemática, apontam quais são os periódicos nacionais existentes no campo da terapia ocupacional: Revista de Terapia Ocupacional da Universidade de São Paulo, Cadernos de Terapia Ocupacional da UFSCar, Revista do Centro de Estudos de Terapia Ocupacional (CETO), Revista Baiana de Terapia Ocupacional e Cadernos de Terapia Ocupacional do GES.TO (Grupo de Estudos Profundos de Terapia Ocupacional). Neste estudo, essa indicaçáo foi utilizada para a revisão de literatura.

O período considerado para a revisão foi o dos últimos 10 anos (2003 a 2012). Os estudos foram selecionados através do título e da leitura dos resumos segundo os seguintes critérios de inclusão: foram analisados estudos de abordagem quantitativa, qualitativa ou mista, estudos de revisão bibliográfica, estudos referentes a todas as áreas de atuação na terapia ocupacional e sem limitações em relação à população estudada. Foram excluídos trabalhos que não eram referentes ao tema proposto, ou seja, que não utilizavam ou não faziam referência ao conceito de cotidiano. Também não foram utilizados editorais, sumários, textos relacionados a apresentaçóes em congressos, cartas, trabalhos publicados apenas na forma de resumo ou artigos em que não foi possível o acesso ao texto completo.

Os estudos foram lidos na integra, avaliados com o objetivo de verificar se os aspectos metodológicos e os resultados da pesquisa eram válidos para serem ponderados nessa revisão, no sentido de fornecerem elementos para análise acerca da temática sobre cotidiano e terapia ocupacional.

Foi realizada uma síntese na forma narrativa, ou seja, uma síntese qualitativa. Foram comparados os estudos selecionados procurando-se encontrar similaridades e diferenças na definição e no uso dos conceitos de atividade e ocupaçâo na literatura referente à terapia ocupacional.

\section{Resultados}

Nas revistas nacionais de terapia ocupacional foram considerados todos os artigos disponíveis nos últimos dez anos (2003 a 2012). A Revista de Terapia Ocupacional da USP publicou 29 volumes nos últimos 10 anos, contendo 239 artigos (sem considerar os editorais), dos quais foram selecionados 5 artigos. A revista Cadernos de Terapia Ocupacional da UFSCar publicou 24 volumes nos últimos 10 anos, contendo 190 artigos (sem considerar os editorais, sumários e resumos), dos quais foram selecionados 4 artigos. A Revista do Centro de Estudos de Terapia Ocupacional publicou 6 volumes nos últimos 10 anos, contendo 40 artigos (sem considerar os editorais e textos relacionados a apresentaçóes em congressos), dos quais foram selecionados 2 artigos. A Revista Baiana de Terapia Ocupacional publicou 4 volumes nos últimos 10 anos, contendo 24 artigos (sem considerar os editorais, sumários e resumos), 1 artigo foi selecionado. A revista Cadernos de Terapia Ocupacional do GES.TO publicou 1 volume nos últimos 10 anos, contendo 4 artigos (sem considerar relatórios e entrevistas) e nenhum de seus artigos foi selecionado. No total foram considerados 64 volumes, contendo 497 artigos, entre os quais foram selecionados 12 artigos para leitura na íntegra.

\subsection{Instrumentos}

A coleta de dados foi realizada a partir da leitura na íntegra de cada estudo, com o preenchimento do formulário de avaliação, no qual foram registrados os aspectos centrais de cada pesquisa. O formulário foi preenchido segundo os autores, o ano de publicação, a metodologia, as concepçôes do estudo em relação 
ao conceito de cotidiano, os principais resultados encontrados e as consideraçóes finais do estudo.

\section{Resultados e discussão}

Dos 12 estudos encontrados havia 3 revisóes de literatura narrativa, 1 relato de experiência e 3 estudos que combinavam metodologias qualitativas e quantitativas. Dos 5 estudos que utilizaram abordagem qualitativa, 4 utilizaram a análise de conteúdo e em 1 a análise foi realizada através da técnica do discurso do sujeito coletivo. Assim, em estudos relacionados ao conceito de cotidiano ou vida cotidiana dos sujeitos alvo dea pesquisa em terapia ocupacional no Brasil nota-se a tendência para o uso de metodologias qualitativas. Esta opção parece pertinente, na medida em que o conceito de cotidiano está relacionado à compreensão do sujeito que tem uma vida individual, em um ambiente social, no qual os modos de produção e as relaçôes sociais estáo sempre influenciando o cotidiano das pessoas.

Segundo Minayo (2004), as pesquisas qualitativas incorporam tanto o significado quanto a intencionalidade vinculados aos atos, relaçōes e estruturas sociais. Os apontamentos de Benetton, Tedesco e Ferrari (2003) reforçam tais considerações ao ressaltarem que, a partir do século XIX, o cotidiano é discutido e entendido como elemento constitutivo da trama social.

Entre os artigos estudados, 5 não apresentaram com clareza a definiçáo do conceito de cotidiano que estava sendo utilizada (COSTABILE; BRUNELLO, 2005; LOPES; GRACIA, 2010; MATSUKURA; MENECHELI, 2011; TAVARES et al., 2012; ALENCAR; TERADA, 2012).

Outros estudos basearam-se em autores da filosofia como Lefebvre e Lukács para conceituar cotidiano (BENETTON; TEDESCO; FERRARI, 2003; GALHEIGO, 2003). Os artigos relatam que, segundo esses autores, a vida cotidiana é uma sequência de acontecimentos vividos no dia a dia, o centro da práxis, onde se produzem e reproduzem as relaçóes sociais. A vida cotidiana permite conhecer a própria sociedade, já que existe uma trama ponderando a relação entre ação política e o cotidiano.

O conceito de cotidiano, advindo da obra de Ágnes Heller, também foi abordado em 4 artigos (BENETTON; TEDESCO; FERRARI, 2003; GALHEIGO, 2003; RIBEIRO; PIMENTEL, 2005; MASTROPIETRO; SANTOS; OLIVEIRA, 2006). Heller $(2000,2002)$ define que o cotidiano está no centro do acontecer histórico e que a vida cotidiana é heterogênea e varia conforme contexto, classe, gênero e idade. A autora indica algumas das esferas que compóem a vida cotidiana: o trabalho, a família, o lazer, as relaçóes sociais. O cotidiano é a vida de todos os dias, de todos os homens, o homem nasce inserido em sua cotidianidade; é o mundo no qual a repetição das atividades permite a recriação permanente da vida social.

$\mathrm{Na}$ vida cotidiana, as atividades com as quais formamos o mundo e as atividades com as quais formamos a nós mesmos coincidem. Para a maioria dos homens, a vida é a vida cotidiana (HELLER, 2002).

Esses autores oferecem um suporte teórico sobre o cotidiano que pode fundamentar e auxiliar as reflexóes e a prática da terapia ocupacional, contribuir para uma forma de pensar e fazer do profissional na atenção ao cliente e à família dele, nas instituições que o cliente frequenta, e nas políticas públicas para as populações que são alvo de atenção em terapia ocupacional.

Além disso, foram utilizados autores terapeutas ocupacionais para fundamentar o conceito de cotidiano (RIBEIRO; PIMENTEL, 2005; MASTROPIETRO; SANTOS; OLIVEIRA, 2006; DUARTE; UCHÔA-FIGUEIREDO, 2010), como Marisa Takatori $(2001,2003)$, que relata que para a terapia ocupacional o cotidiano é entendido como uma sucessão de acontecimentos vividos, que incluem espaços sociais, tempos diversos, pessoas e objetos variados. O cotidiano possibilita ao sujeito expor seu estilo de ser, que, ao mesmo tempo, é compartilhado e reconhecido pelo outro, construindo sua história pessoal e social. O cotidiano é uma forma de viver sua própria história.

O cotidiano faz parte da vida do sujeito e o sujeito se constitui a partir da sua vida cotidiana, são partes inter-relacionadas e constitutivas entre si. A vida cotidiana é o cenário em que ocorre a inserção no mundo compartilhado, social e cultural (TAKATORI, 2001).

Assim, percebe-se que o conceito de cotidiano, considerado nos estudos de terapeutas ocupacionais, se estabelece na relação entre aquilo que é singular do sujeito com o que é coletivo e social. Há um foco no dia a dia do indivíduo, nos pequenos acontecimentos e açôes, nos detalhes da construção da história do sujeito, em articulação com o contexto social, as formas de produção, as diretrizes políticas, a organização social. O conceito de cotidiano se estabelece na relação do micro com o macro, se constrói na articulação entre o zoom focado na vida do sujeito e a lgrande ocular que capta os processos de produção social. 
Entre os estudos analisados, Galheigo (2003, p. 107) realiza avanços no uso do conceito de cotidiano no campo da terapia ocupacional. Segundo a autora, é a reflexão sobre as práticas sociais que cruzam o cotidiano que possibilita a compreensão da realidade social e abre as portas para a sua modificação. Na medida em que os estudos sobre o cotidiano "incorporam a subjetividade, a cultura, a história e o poder social como elementos que influenciam na compreensão do fenômeno, eles definitivamente rompem com qualquer leitura de caráter mais positivista”. Assim, o cotidiano surge na terapia ocupacional como uma busca de fazer uso de conceitos que se afinem às leituras e proposiçóes críticas da ação da terapia ocupacional.

O conceito de cotidiano não pode se restringir à ideia daquilo que é feito dia após dia, pois abrange como o sujeito vê a si mesmo, como constrói sua identidade, como participa da vida comunitária e também se refere às formas de organização social.

\section{Uma perspectiva teórico-metodológica}

No desenvolvimento das concepçóes teóricas utilizadas em terapia ocupacional, o conceito de hábitos e atividades de vida diárias se encontra nas origens da terapia ocupacional. E, percorrendo caminhos diferentes, esses conceitos iniciaram discussōes que mais tarde repercutem no uso do conceito de cotidiano na terapia ocupacional.

Os hábitos são associados à vida do dia a dia, são únicos para cada sujeito, são mecanismos para que as pessoas se acostumem a efetuar todo dia o necessário e o desejado de maneira eficiente. A rotina e os hábitos são entendidos como característicos da cotidianidade e introduzem certa sucessão nas atividades da vida cotidiana (BENETTON; TEDESCO; FERRARI, 2003).

A principal herança de Slagle e seu programa de treinamento de hábitos para a terapia ocupacional é que ela rompe com o paradigma médico de enfrentamento de sintomas para um paradigma fundamentado no fazer para construir cotidianos, apesar das doenças ou deficiências (BENETTON; TEDESCO; FERRARI, 2003).

Assim, desde sua origem a terapia ocupacional já apontava para uma aproximaçáo conceitual com as reflexões das ciências sociais; que leva em conta não apenas a doença, mas a subjetividade e a história dos sujeitos, seus modos de fazer e suas relaçóes sociais.

A ideia de vida diária também vem sendo utilizada pela terapia ocupacional desde suas origens. Porém os conceitos de atividades de vida diária e prática "são a-históricos, sendo utilizados de forma indiscriminada e descontextualizada nos livros e nas práticas de terapia ocupacional" (GALHEIGO, 2003, p. 107).

Nesse contexto, a terapia ocupacional caminhou do treinamento das atividades de vida diária para a ressignificação do cotidiano. A concepção sobre o cotidiano surge com a intenção de transformar os conceitos de atividades de vida diária e atividades de vida prática, que inicialmente tinham uma perspectiva positivista (GALHEIGO, 2003).

O conceito de cotidiano na produçáo e no discurso da terapia ocupacional implica em uma mudança na proposição teórica e metodológica da profissão. A prática da terapia ocupacional baseia-se na contextualização histórica do indivíduo e na sua possibilidade de participação social (GALHEIGO, 2003).

Assim, reafirmando a origem da reflexão sobre hábitos, ou problematizando a conceituação sobre atividades de vida diária os autores colocam o cotidiano como um conceito que define uma posição teórica da terapia ocupacional que rompe com uma interpretação médica e positivista dos cuidados em saúde e se preocupa como a subjetividade do sujeito, suas atividades no dia a dia e sua inserção social (GALHEIGO, 2003; BENETTON; TEDESCO; FERRARI, 2003).

A utilização do conceito de cotidiano em terapia ocupacional indica um caminho teórico e metodológico trilhado pela profissão, que procura ir além do estudo dos fenômenos concretos, repetitivos e sintomáticos (como utilizado no paradigma médico), para focalizar também no que é único e ocorre em conexáo com o contexto social. O conceito de cotidiano permite que a terapia ocupacional mantenha seu objeto de estudo e prática com um olhar próprio, enxergando o sujeito em suas singularidades e suas relaçôes sociais e não apenas em suas funçôes físicas e funcionalidade na execução de determinadas atividades.

\section{$6 \mathrm{O}$ adoecimento como uma ruptura na vida cotidiana}

O conceito de cotidiano também foi utilizado nas pesquisas dos terapeutas ocupacionais na reflexáo sobre como o adoecimento causa transformaçóes na vida cotidiana tanto do sujeito que adoeceu como das pessoas a sua volta.

Por exemplo, doenças crônicas acarretam limitações no desempenho funcional que limitam a realização de tarefas no dia a dia, transformando 
o cotidiano do sujeito (TAVARES et al., 2012), ou a presença da criança com deficiência, que transforma a vida cotidiana das famílias (RIBEIRO; PIMENTEL, 2005).

A dor também causa dificuldades na realização de atividades de vida diária (básicas e instrumentais), consequentemente o sujeito necessita de ajuda de outras pessoas para realizar afazeres domésticos. Pessoas afastadas do trabalho vivenciam uma rotina que se organiza a partir de consultas médicas, exames e perícia junto ao INSS. Além disso, a dor prejudica o lazer e as atividades sociais. As dificuldades para realizar atividades antes desempenhadas afetam os papéis sociais, a relação entre as pessoas, o contexto social e a saúde mental. A dor pode gerar incapacidade para trabalhar e deixar o sujeito mais tempo em casa, reduzindo as atividades que a pessoa costumava fazer e construindo um cotidiano em torno do tratamento (ALENCAR; TERADA, 2012).

A vida cotidiana das pessoas também se transforma após transplante de medula óssea (TMO), inicialmente o dia se preenche por atividades de autocuidado e após algum tempo desperta-se para um novo cotidiano, diferente daquele antes do transplante. Após o TMO, as necessidades subjetivas dos sujeitos assumem uma dimensão empobrecida, os cuidados restringem-se à manutençáo do corpo biológico; conforme são liberados dessas limitações, os sujeitos retomam o sentido de domínio sobre a própria vida e reconstroem seu cotidiano. $\mathrm{O}$ transplante de medula óssea causa uma ruptura brutal no cotidiano e também a possibilidade de uma nova construção (MASTROPIETRO; SANTOS; OLIVEIRA, 2006).

Esses exemplos demonstram o impacto da doença no cotidiano do sujeito e das pessoas próximas a ele. Após o aparecimento de uma doença, a vida cotidiana pode tomar outro rumo, o que antes era importante pode se tornar secundário, ou uma atividade que antes era realizada com facilidade pode se tornar um desafio e novas aprendizagens podem ser necessárias.

Muitas vezes, o sujeito terá que ressignificar suas experiências, buscar na vida antes do adoecimento sentido para sua vida, mas também encontrar novos caminhos de construção da sua subjetividade, de quem ele é, o que gosta de fazer, como participa dos modos de produção social e com quem se relaciona.

Outra questão abordada nos estudos é a importância da continuidade da vida cotidiana, apesar da doença (DUARTE; UCHÔA-FIGUEREDO, 2010). Mesmo que a doença promova transformaçōes, o sujeito deve conseguir dar continuidade a sua história de vida a partir das atividades que realiza no dia a dia, retomando e reinventando ocupaçóes significativas.

Estudo de Duarte e Uchôa-Figueredo (2010) relata como idosos com hipertensão arterial ou diabetes mellitus conseguem realizar o que precisam, em casa e no lazer, acreditam ser habilidosos no que fazem e realizam atividades significativas. Eles organizam seu tempo, planejam antes de executar e exercem pelo menos um papel social na vida. Eles continuam realizando uma gama de atividades de vida prática, de lazer e atividades compartilhadas; conseguem envelhecer de forma saudável e se adaptar às mudanças físicas, psíquicas e sociais.

Os acontecimentos marcantes da vida estão impressos no cotidiano, as transformaçóes ocorridas com os sujeitos, assim como a continuidade de sua história de vida, acontecem no cotidiano. As mudanças subjetivas e objetivas que acontecem com o sujeito atravessam a vida cotidiana.

\section{O cotidiano dos sujeitos}

O conceito de cotidiano também foi utilizado nas pesquisas para embasar a descrição e análise da vida cotidiana dos sujeitos que eram foco dos estudos. Os estudos mostram o interesse da terapia ocupacional pelo que as pessoas fazem no dia a dia, como se relacionam, e como o ambiente social influencia as possibilidades de os sujeitos realizarem atividades.

Lopes e Garcia (2010) descrevem o cotidiano de trabalho durante o dia, estudo à noite e poucas atividades de lazer nos finais de semana para os adolescentes trabalhadores da UFSCar. Relatam que devido à necessidade financeira, os adolescentes têm necessidade de trabalhar. Porém, o cansaço do trabalho durante o dia prejudica o estudo à noite. Os autores problematizam a má qualidade do ensino público e do ensino à noite, ao mesmo tempo em que apontam a escola como caminho para realização dos projetos de vida desses adolescentes.

Ribeiro e Pimentel (2005) identificam que o cotidiano das famílias de crianças com deficiência se desenrola em torno dos cuidados com a criança. Outras atividades são delegadas para segundo plano, com exceção das atividades remunerativas, quando são realizadas pelo pai. O cotidiano das mães é composto pelo cuidar da criança deficiente e pelo trabalho doméstico ou remunerado, e foram apontadas dificuldades para realizar atividades de lazer.

O estudo de Matsukura e Menecheli (2011) complementa esses achados identificando a sobrecarga 
de trabalho no cotidiano de máes de crianças autistas, ao mesmo tempo em que acompanhar, dia após dia, o desenvolvimento dessas crianças é um dos maiores prazeres vividos pelas mães. Também foram relatadas a relação de dependência das crianças autistas com as mães e as dificuldades das mães para frequentar ambientes externos com as crianças. Foi analisada a rotina das crianças autistas, que gira apenas em torno dos tratamentos e da escola.

Outro aspecto apontado pelas pesquisas é como a rotina institucional é determinante na construção do cotidiano do sujeito. Para a pessoa que está institucionalizada, o ambiente externo tem uma influência marcante nas possibilidades do que o indivíduo pode fazer durante o dia.

Pirágine e Auler (2010) relatam como a rotina institucional padroniza o comportamento de pessoas com transtornos mentais em hospitais psiquiátricos, afetando diretamente a personalidade dos sujeitos habitantes. As autoras descrevem o programa da terapia ocupacional em um hospital, composto por oficinas, acompanhamento terapêutico, festas e reuniōes, e refletem sobre as transformações ocorridas no cotidiano dos sujeitos a partir das atividades oferecidas por esse programa.

O cotidiano de crianças com deficiência nas escolas também é objeto de análise de Costabile e Brunello (2005). As autoras relatam os progressos das crianças autistas que frequentavam escolas regulares e identificaram: maior socialização, independência e autonomia em atividades de vida prática, diversificação de brincadeiras, compreensão de regras, mudança de atitude frente a outros, conquistas na área pedagógica e ampliação da comunicação verbal e não verbal. $\mathrm{Na}$ convivência cotidiana na escola há a oportunidade de aprendizagem e de se estabelecerem novas relaçóes.

Assim, percebe-se que o conceito de cotidiano pode ser utilizado para refletir sobre como as pessoas organizam a vida e como a doença gera a necessidade de priorizar as atividades relacionadas ao tratamento. O cotidiano também é colocado como elemento centralizador na análise de como o contexto social transforma o dia a dia das pessoas, identificando-se todos os desdobramentos que se dão a partir dessas transformaçóes.

\section{Atenção em terapia ocupacional}

Estudos também relataram (ou discorreram sobre) a importância da reflexão sobre o cotidiano na prática da terapia ocupacional (GALHEIGO,
2003; BENETTON; TEDESCO; FERRARI, 2003; RIBEIRO; PIMENTEL, 2005; MASTROPIETRO; SANTOS; OLIVEIRA, 2006; LUVIZARO; GALHEIGO, 2011; PIRÁGINE; AULER, 2010; ALENCAR; TERADA, 2012; TAVARES et al., 2012). As pesquisas evidenciam como são múltiplas as possibilidades de açáo da terapia ocupacional na perspectiva de auxiliar a construção de uma vida cotidiana significativa para o sujeito.

A vida cotidiana do sujeito se revela no entroncamento da realidade exterior $\mathrm{e}$ da realidade psíquica, na rede de suas relações sociais, nas atividades costumeiras de autocuidado e automanutenção, nas manifestaçôes de solidariedade (GALHEIGO, 2003, p. 108).

A terapia ocupacional tem uma posição privilegiada ao poder colaborar para a elaboração crítica do cotidiano do sujeito.

$\mathrm{Na}$ terapia ocupacional é necessário garantir a humanização no tratamento e recriar o cotidiano a partir da ruína e das partes vivas que resistiram à crise (MASTROPIETRO; SANTOS; OLIVEIRA, 2006).

Também é importante auxiliar as famílias a reorganizarem sua vida cotidiana (RIBEIRO; PIMENTEL, 2005). Náo apenas o sujeito que adoeceu deve receber atenção para reconstruir sua vida, mas também aqueles que estão à sua volta, vivem as transformações no seu cotidiano e podem receber cuidados e orientaçóes da terapia ocupacional.

A terapia ocupacional pode atuar na construção da moradia dos sujeitos, transformando os lugares de habitar em espaços que se configuram no cotidiano - o ser humano necessita ser acolhido pelo ambiente em que se insere (LUVIZARO; GALHEIGO, 2011).

Nas instituições, a terapia ocupacional pode construir um cotidiano individual e não alienante, como a rotina institucional, ajudando no resgate da história de vida do sujeito e na construçáo de uma nova história (PIRÁGINE; AULER, 2010). Também pode contribuir no reordenamento institucional dos abrigos, por exemplo (LUVIZARO; GALHEIGO, 2011).

Além disso, é importante auxiliar o sujeito na realização das tarefas do dia a dia, oferecendo um suporte no enfrentamento da situaçáo criada pela doença e ajudando na reconstrução do cotidiano (ALENCAR; TERADA, 2012).

$\mathrm{O}$ atendimento em terapia ocupacional também pode ser uma estratégia utilizada para promover a 
reflexão sobre o cotidiano do sujeito e a reorganização de hábitos, rotinas e papéis. A terapia ocupacional auxilia os sujeitos a remodelarem sua história de vida e ressignificarem o cotidiano depois das transformaçóes ocorridas devido à doença (TAVARES et al., 2012).

Segundo o método de terapia ocupacional dinâmica, no setting da terapia ocupacional se promove um espaço de fazer, criar, construir e reconstruir a história do sujeito; nesse processo percebe-se que um outro cotidiano é possível (BENETTON; TEDESCO; FERRARI, 2003).

\section{Considerações finais}

Os sujeitos inseridos em práticas e intervençôes em terapia ocupacional, em geral, vivenciaram uma ruptura na sua vida cotidiana. $\mathrm{Na}$ atenção a essas pessoas é preciso reconhecer o que mudou, as ocupaçôes que se tornaram improváveis, ou que precisam de adaptaçôes para sua realização, mesmo que muitas vezes isso represente um momento de luto pelo que se perdeu. O terapeuta ocupacional busca, com o sujeito, maneiras para ele não se fechar na impossibilidade, resgatar sua história de vida, a história de suas ocupaçôes, descobrindo um caminho de continuidade entre o passado e o presente e também de continuidade com o futuro, abrindo espaço para o novo, para a redescoberta de outras e novas ocupaçóes para o sujeito.

Nesse processo, o sujeito se identifica com o que faz, se estabelecem novos papéis sociais. O cotidiano se reconstrói com as pessoas à sua volta, no contexto em que ele se insere. Se o cotidiano se transforma, o sujeito também se transforma; uma ruptura na vida cotidiana e a ressignificação desse cotidiano não acontecem sem uma transformação subjetiva do sujeito. O inverso também pode ocorrer, se o sujeito se transforma, essa mudança irá se refletir em sua vida cotidiana, pois a vida cotidiana e as particularidades do sujeito caminham de mãos dadas, imersos em seu contexto social.

$\mathrm{Na}$ construção desses caminhos, a teoria do cotidiano como descrita por Heller (2000) pode oferecer um suporte na reflexão e transformação do cotidiano do sujeito. O conceito de heterogeneidade, por exemplo, define que a vida cotidiana é composta de diferentes esferas, ou gamas de atividades, como descanso, trabalho, lazer e atividade social (HELLER, 2000), e pode ser usado para refletir sobre como a pessoa compóe a sua vida cotidiana, analisando "como" e "se" existem atividades nas diferentes esferas, por exemplo.
Já o conceito de hierarquia, que considera que uma atividade ocupa um lugar central e determinante e a ela se subordinam todas as demais formas de atividade (HELLER, 2000), pode ser útil na reflexão sobre como o adoecimento transforma as prioridades das atividades que são realizadas no dia a dia, o que muda toda a organizaçáo da vida cotidiana.

São diversas as possibilidades do uso do conceito de cotidiano na pesquisa e na prática da terapia ocupacional e o presente estudo evidencia que esse construto/conceito soma ao aporte teórico vinculado ao conhecimento em terapia ocupacional contemporânea brasileira.

\section{Referências}

ALENCAR, M. C. B.; TEREDA, T. M. O afastamento do trabalho por afecçôes lombares: repercussóes no cotidiano de vida dos sujeitos. Revista de Terapia Ocupacional da USP, São Paulo, v. 23, n. 1, p. 44-51, 2012.

BENETTON, M. J.; TEDESCO, S.; FERRARI, S. Hábitos, cotidiano e Terapia Ocupacional. Revista CETO, São Paulo, v. 8, n. 8, p. 27-40, 2003.

CASTRO, E. D.; LIMA, E. M. F. A.; BRUNELLO, A. I. B. Atividades humanas e Terapia ocupacional. In: DE CARLO, M. M. R. P.; BARTALOTTI, C. C. (Org.). Terapia Ocupacional no Brasil: Fundamentos e perspectivas. São Paulo: Plexus, 2001. p. 41-59.

COSTABILE, C.; BRUNELLO, M. I. B. Repercussōes da inclusão escolar sobre o cotidiano de crianças com deficiência: um estudo a partir do relato das famílias. Revista de Terapia Ocupacional da USP, São Paulo, v. 16, n. 3, p. 124-130, 2005.

DRUMMOND, A. F. Fundamentos da Terapia Ocupacional. In: CAVALCANTI, A.; GALVÃO, C. (Ed.). Terapia Ocupacional: Fundamentação e prática. Rio de Janeiro: Guanabara Koogan, 2007. p. 10-17.

DUARTE, G. P.; UCHÔA-FIGUEREDO, L. R. A vida cotidiana e a qualidade de vida de pacientes atendidos na atenção primária de saúde. Cadernos de Terapia Ocupacional da UFSCar, São Carlos, v. 18, n. 1, p. 19-33, 2010.

FRANCISCO, R. B. Terapia ocupacional. 2. ed. Campinas: Papirus, 2001. PMCid:30108.

GALHEIGO, S. M. O cotidiano na terapia ocupacional: cultura subjetividade e contexto histórico-social. Revista de Terapia Ocupacional da USP, São Paulo, v. 14, n. 3, p. 104-109, 2003.

GALVÂO, C. M.; SAWADA, N. O.; TREVIZAN, M. A. Revisão sistemática: recurso que proporciona a incorporação das evidências na prática da enfermagem. Revista Latino Americana de Enfermagem, Ribeirão Preto, v. 12, n. 3, p. 549-556, 2004. PMid:15303213. http:// dx.doi.org/10.1590/S0104-11692004000300014

HELLER, A. O cotidiano e a história. São Paulo: Paz e Terra, 2000. 
HELLER, A. Sociología de la vida cotidiana. Barcelona: Ed. Península, 2002.

LIMA, E. M. F. A.; PASTORE, M. D. N.; OKUMA, D. G. As atividades no campo da Terapia Ocupacional: mapeamento da produçáo científica dos terapeutas ocupacionais brasileiros de 1990 a 2008. Rev. Revista de Terapia Ocupacional da USP, São Paulo, v. 22, n. 1, p. 68-75, 2011.

LOPES, R. E.; GARCIA, D. B. Problemas e perspectivas escolares e de trabalho no cotidiano dos meninos e meninas trabalhadores da UFSCar. Cadernos de Terapia Ocupacional da UFSCar, São Carlos, v. 18, n. 3, p. 247-261, 2010.

LUVIZARO, N. A.; GALHEIGO, S. M. Consideraçôes sobre o cotidiano e o habitar de crianças e adolescentes em situação de acolhimento institucional em abrigo. Revista de Terapia Ocupacional da USP, São Paulo, v. 22, n. 2, p. 191-192, 2011.

MASTROPIETRO, A. P.; SANTOS, M. A.; OLIVEIRA, E. A. Sobreviventes do transplante de medula óssea: construção do cotidiano. Revista de Terapia Ocupacional da USP, São Paulo, v. 17, n. 2, p. 64-71, 2006.

MATSUKURA, T. S.; MENECHELI, L. A. Famílias de crianças autistas: demandas e expectativas referentes ao cotidiano de cuidados e ao tratamento. Cadernos de Terapia Ocupacional da UFSCar, São Carlos, v. 19, n. 2, p. 137-152, 2011.

MINAYO, M. C. S. O desafio do conhecimento: pesquisa qualitativa em saúde. 8. ed. São Paulo: Hucitec, 2004.

PIRÁGINE, M.; AULER, L. M. D. G. Os significados do cotidiano. Revista CETO, São Paulo, v. 12, n. 12, p. 9-13, 2010.

RIBEIRO, V. O.; PIMENTEL, A. M. As mudanças no cotidiano de famílias que possuem filhos com deficiência. Revista Baiana de Terapia Ocupacional, v. 2, n. 1, p. 11-16, 2005.

TAKATORI, M. A. Terapia ocupacional no processo de reabilitação: construção do cotidiano. O Mundo da Saúde, São Paulo, v. 25, n. 4, p. 371-377, 2001.

TAKATORI, M. O brincar no cotidiano da criança com deficiência física: reflexóes sobre a clínica da terapia ocupacional. São Paulo: Atheneu, 2003.

TAVARES, A. A. et al. (Re) Organizaçáo do cotidiano de indivíduos com doenças crônicas a partir da estratégia de grupo. Cadernos de Terapia Ocupacional da UFSCar, Sáo Carlos, v. 20, n. 1, p. 95-105, 2012. http://dx.doi. org/10.4322/cto.2012.011

\section{Contribuições dos Autores}

Mariana Moraes Salles realizou a concepção da pesquisa, a coleta e análise de dados, efetivou a organização dos resultados, discussão e redação do texto. Thelma Simóes Matsukura orientou todas as etapas do estudo, participou da concepção da pesquisa, contribuiu na discussão dos resultados e realizou revisão crítica do texto.

\section{Notas}

${ }^{1}$ O presente artigo integra o projeto de pesquisa realizado durante estágio pós-doutoral de título "Vida cotidiana e saúde mental: contextualizando as ocupaçôes e o uso do tempo de usuários de centros de atençáo psicossocial”, desenvolvido no Programa de Pós-graduação em Terapia Ocupacional, Departamento de Terapia Ocupacional, Universidade Federal de São Carlos. Pesquisa financiada pela Fundação de Amparo à Pesquisa do Estado de São Paulo - FAPESP - Processo no 2011/23424-5. 